\title{
A novel role for autologous tumour cell vaccination in the immunotherapy of the poorly immunogenic B16-BL6 melanoma
}

\author{
J. D. GEIGER, P. D. WAGNER, S. SHU AND A. E. CHANG \\ Division of Surgical Oncology, Department of Surgery, University of Michigan, Ann Arbor, MI 48109, USA
}

\begin{abstract}
The growth of immunogenic tumours stimulates the generation of tumour-sensitized, but not functional, pre-effector $T$ cells in the draining lymph nodes. These pre-effector cells can mature into effector cells upon in-vitro stimulation with anti-CD3 and IL-2. In the current study, using a defined, poorly immunogenic tumour, B16-BL6 melanoma, the pre-effector cell response was not evident during progressive tumour growth but was elicited by vaccination with irradiated tumour cells admixed with Corynebacterium parvum. After anti-CD3/IL-2 activation, these cells were capable of mediating the regression of established pulmonary metastases. The efficacy of the vaccine depended on the doses of both tumour cells and the adjuvant. While higher numbers of tumour cells were more effective, an optimal dose $(12.5 \mu \mathrm{g})$ of $C$. parvum was required. The dose of irradiation was not a critical factor. After vaccination, kinetic studies revealed that the pre-effector cell response was evident 4 days later and declined after 14 days. These observations illustrate the potential role of active immunization in the cellular therapy of cancer. Surgical Oncology 1992; 1: 199-208.
\end{abstract}

Keywords: immunotherapy, melanoma, metastasis, T-cells, vaccine.

\section{INTRODUCTION}

Central to tumour immunology is the question of whether antigens recognizable by the host immune system exist on the surface of tumour cells. Clearly, definable tumour-specific antigens can be demonstrated in many animal tumour models [1, 2]. These studies suggest the existence of similar antigens on human cancer cells and stimulated multiple attempts over the course of the last three decades to immunize patients with their own tumours [3-5]. Most of these studies were performed empirically with little evidence of a specific immune response.

Studies on immunological mechanisms of tumour rejection have identified the cellular effector arm of

Correspondence: Dr A. E. Chang, 2920 Taubman Center, University of Michigan Medical Center, 1500 E. Medical Center Drive, Ann Arbor, MI 48109-0331, USA.

This paper was read before the 45th Annual Cancer Symposium of the Society of Surgical Oncology, New York, NY, 16 March, 1992. the immune system as crucial in mediating tumour destruction. In fact, in a variety of animal models, the transfer of specifically tumour-sensitized lymphocytes to the tumour-bearing host can mediate therapeutic effects in rejecting established localized and metastatic cancers [6-8]. Although theoretically attractive, this adoptive immunotherapy approach has received relatively little attention in humans because of difficulties associated with generating large numbers of correctly sensitized autologous cells. The application of adoptive immunotherapy for the treatment of human cancer therefore requires the development of methods to isolate and propagate in-vitro antitumour-reactive T-cells from patients. One potential cell source, which is suitable for adoptive immunotherapy, has been tumour-infiltrating lymphocytes (TIL), owing to the demonstration of their potent antitumour properties in animal experiments $[9,10]$. While the therapeutic efficacy of human TIL expanded with IL-2 is being intensively evaluated in clinical trials, initial results are encouraging [11]. 
In the past few years, we have developed an additional method to generate large quantities of immune effector cells from the tumour-bearing host. The initial observations were made with several immunogenic murine tumours that during progressive tumour growth, draining lymph nodes (LN) were found to contain tumour-sensitized T-cells [12, 13]. Although these $L N$ cells did not express overt antitumour reactivity, they could be further sensitized in vitro with anti-CD3 and IL-2 to differentiate into functional immune effector cells capable of mediating immunologically specific regression of established pulmonary metastases in adoptive immunotherapy [14-16]. As immune effector cells could only be generated from tumour-bearing but not normal mice, the cells in the draining LN were therefore termed 'pre-effector' cells. However, due to several characteristics of the pre-effector cell response, extrapolation of these studies in the design of clinical adoptive immunotherapy in humans is difficult. First, the presence of preeffector cells within $L N$ draining progressive tumours follow rather strict kinetics depending on the duration of tumour growth [15]. Clinically, the duration of tumour growth in patients is variable at the time of presentation and is difficult to assess. Secondly, the pre-effector cell response and subsequent generation of therapeutic anti-CD3/IL-2 activated effector cells has been defined only in the context of immunogenic tumours. The immunogenicity of human tumours is not clear and is presumably weak due to their spontaneous origin [17]. Hence, human tumours may elicit a weak preeffector response.

Therefore, we have selected the poorly immunogenic murine B16-BL6 (BL6) melanoma to define clinically applicable methods to generate anti-CD3/ IL-2 activated effector cells for adoptive immunotherapy. This tumour failed to induce systemic immunity by a variety of active immunization procedures; and indeed we found that the progressive growth of the BL6 tumour did not elicit a detectable pre-effector cell response. However, pre-effector cells were generated in the draining $L N$ in response to priming the host with tumour cells admixed with the bacterial adjuvant, Corynebacterium parvum (C. parvum). We have further demonstrated that vaccination of the host with irradiated tumour cells, admixed with $C$. parvum, was effective in eliciting a pre-effector cell response. In contrast to unirradiated
BL6 tumour cells to prime the host, irradiated tumour cells lacked tumourigenicity and hence can be easily adapted for clinical use. We therefore have systematically defined the conditions and requirements for the use of an effective vaccine in the BL6 melanoma model. These studies suggest that a component of active immunization can facilitate the production of specific tumour-immune lymphocytes for adoptive immunotherapy and may be applicable in the treatment of human malignancy.

\section{MATERIALS AND METHODS}

\section{Mice}

Female C57BL/6J (B6) mice, 6-8 weeks old, were purchased from the Jackson Laboratory, Bar Harbor, ME. They were maintained in specific pathogen-free environments and were used for experiments at the age of 10 weeks or older.

\section{Tumour}

The B16-BL6 (BL6) melanoma is a tumour of spontaneous origin syngeneic to the B6 mouse that has been studied extensively $[18,19]$. The tumour was kindly provided by Dr E. Gorelik (University of Pittsburgh), and was an early passage of the original BL6 described by Hart [18]. Tumour cells were maintained by in-vitro passage in complete media (CM). CM consisted of RPMI 1640 medium supplemented with $10 \%$ heat-inactivated fetal calf serum, $0.1 \mathrm{~mm}$ non-essential amino acids, $1 \mu \mathrm{m}$ sodium pyruvate, $2 \mathrm{mM}$ fresh L-glutamine, $100 \mu \mathrm{g} \mathrm{ml}{ }^{-1}$ streptomycin, $1000 \mathrm{ml}^{-1}$ penicillin, $50 \mu \mathrm{g} \mathrm{ml} l^{-1}$ gentamicin, $0.5 \mu \mathrm{g}$ $\mathrm{ml}^{-1}$ fungizone (all from GIBCO, Grand Island, NY) and $5 \times 10^{-5} \mathrm{M}$ 2-mercaptoethanol (Sigma). Cultured tumour cells were harvested after a short incubation at $37^{\circ} \mathrm{C}$ with a solution containing $0.25 \%$ trypsin and $0.02 \%$ EDTA (GIBCO). Tumour cells were washed with Hanks Balanced Salt Solution (HBSS) prior to intravenous (i.v.) or subcutaneous (s.c.) inoculation.

\section{IL-2}

Human rlL-2 was kindly supplied by the Cetus Corp. (Emeryville, CA) with a specific activity of $6-8 \times 10^{6}$ Cetus $U \mathrm{mg}^{-1}$ protein. In this report, all units of IL-2 
are expressed in Cetus units where 1 Cetus unit is equivalent to 6 International units.

\section{Anti-CD3 mAb}

The YCD3-1 hybridoma cells producing rat IgG2b monoclonal antibody (mAb) directed against the $\mathrm{CD} 3 \varepsilon$ chain of the murine TCR/CD3 complex were produced and kindly provided by Dr Kim Bottomly, Yale University [20]. Antibodies were obtained by injecting hybridoma cells into pristane-primed sublethally irradiated (500 rad) DBA/2 mice and collecting ascites. The $\lg G$ content was determined by ELISA assay.

\section{Draining LN cells}

Tumour growth was initiated by inoculating syngeneic $B 6$ mice s.c. in the flank with $1 \times 10^{6}$ viable BL6 admixed with various doses of $C$. parvum (Burroughs Wellcome Co., Research Triangle Park, NC) suspended in $0.05 \mathrm{ml}$ of HBSS. In this case, tumour growth was evident at day 3. Tumour vaccine was prepared using irradiated tumour cells admixed with various doses of C. parvum and inoculated into syngeneic mice similarly. Routinely, 7-12 days after tumour inoculation or vaccination draining inguinal $L N$ were removed sterilely. Lymphocyte suspensions were prepared by first teasing $L N$ with $20 \mathrm{G}$ needles and then pressing with the blunt end of a $10-\mathrm{ml}$ plastic syringe in HBSS.

\section{Tumour irradiation}

The BL6 tumour cells were suspended in $\mathrm{CM}$ and maintained at $4^{\circ} \mathrm{C}$. Cells were irradiated with 1,000-32,000 cGy using a Gamma Cell 1000 irradiator $1500 \mathrm{cGy} \mathrm{min}^{-1}$, Atomic Energy of Canada, Ltd). Irradiated tumour cells were then washed with HBSS $\times 2$ and resuspended in HBSS for inoculation with an appropriate dose of $C$. parvum.

\section{In-vitro anti-CD3/IL-2 activation of $L N$ cells}

Draining LN cells were stimulated in vitro by incubating approximately $10^{8}$ cells in a $75 \mathrm{~cm}^{2}$ tissue culture flask in $30 \mathrm{ml}$ of $\mathrm{CM}$ with $2.5 \mu \mathrm{g} \mathrm{ml} \mathrm{m}^{-1}$ of anti$\mathrm{CD} 3 \mathrm{mAb}$ at $37^{\circ} \mathrm{C}$ in $5 \%$ atmosphere for 2 days. In some experiments, $4 \times 10^{6}$ LN cells were activated with immobilized anti-CD3 antibody in 24-well tissue culture plates. The cells were harvested, washed, and further cultured at $6 \times 10^{5}$ cells/well in $2 \mathrm{ml}$ of $\mathrm{CM}$ containing $10 \mathrm{U} \mathrm{ml}^{-1}$ of $\mathrm{IL-2}$ in 24-well plates for 3 days. During this period of time, cells proliferated vigorously and the number increased, three- to sixfold. These anti-CD3/IL-2 activated cells were then harvested, washed and resuspended in HBSS for adoptive immunotherapy.

\section{Procedure for adoptive immunotherapy}

B6 mice were injected i.v. with 3-4 $\times 10^{5}$ BL6 tumour cells in $1 \mathrm{ml}$ of HBSS to initiate pulmonary metastases. On day 3 , anti-CD3/IL-2 activated draining $L N$ cells were given i.v. to each mouse. Some mice were also treated with $15,000 \cup \mathrm{IL}-2$ in $0.5 \mathrm{ml}$ HBSS i.p. twice a day for 4 days to enhance the in-vivo function of transferred cells. At this stage, all mice were eartagged and randomized. On day 14-17 of tumour growth the mice were killed, the lungs insufflated with Fekete's solution, and pulmonary metastases enumerated as described previously [8]. Metastatic foci too numerous to count were assigned an arbitrary value of $>250$ because this was the largest number of tumour nodules that could be reliably enumerated.

\section{Statistical analysis}

The significance of differences in numbers of pulmonary metastases between groups was determined by the Wilcoxon rank-sum test. Two sided $P$ values of $<0.05$ were considered significantly different. All groups consisted of at least five mice and no animal was excluded from the statistical analysis.

\section{RESULTS}

\section{Draining LN response to progressive BL6 tumour growth}

We have previously reported that LN draining progressive immunogenic methylcholanthrene-induced (MCA) sarcomas contain lymphocytes which can be secondarily activated in vitro to differentiate into therapeutic effector cells for adoptive immunotherapy [12-16]. The BL6 tumour, being different from MCA sarcomas, has been characterized to be poorly or non-immunogenic and displays a highly 
invasive growth pattern by spontaneously metastasizing after s.c. inoculation [19]. We therefore examined whether progressive BL6 tumour growth would elicit the development of pre-effector cells in tumour-draining LN. B6 mice were inoculated s.c. with $10^{6}$ viable BL6 tumour cells. Some animals were inoculated with viable tumour cells admixed with $C$. parvum, which was utilized as an immune adjuvant. Nine days later, draining inguinal $L N$ were removed and activated by the anti-CD3/IL-2 culture method. This activation resulted in cells expanded approximately three- to six-fold. The activated cells were administered i.v. $\left(5 \times 10^{7} /\right.$ mouse $)$ into mice bearing 3-day established pulmonary metastases (Table 1). IL-2 was given (15,000 U i.p.) twice daily for 4 days starting on the day of cell transfer to promote the in-vitro proliferation of the activated cells. This therapeutic regimen was well tolerated with no evidence of toxicity. Lungs were harvested 14 days after tumour inoculation and pulmonary metastases enumerated in a blinded fashion.

In contrast to our previously reported experience with several immunogenic MCA sarcomas, the progressive growth of the BL6 did not stimulate the sensitization of pre-effector cells in draining LN (Table 1 ) by evidence of the failure of anti-CD3/LL-2 activated cells to mediate the regression of pulmonary metastases. However, the use of $12.5 \mu \mathrm{g}$ of $C$. parvum at the initiation of tumour growth was found to elicit pre-effector cells in the draining $L N$ which upon anti-CD3/IL-2 activation mediated potent antitumour reactivity. The dose of $C$. parvum was criti- cal because a higher dose $(50 \mu \mathrm{g})$ was ineffective. $C$. parvum inoculated without tumour cells did not induce pre-effector cells in the draining LN (data not shown).

\section{Tumourigenicity of irradiated BL6 melanomas}

Although $C$. parvum helped to stimulate a preeffector cell response, the vaccination site showed progressive tumour growth and no systemic immunity was developed. Therefore, application of these approaches to generate immune cells in a clinical setting can be problematic. It is practical to establish a non-tumourigenic vaccine which would enable sensitization of pre-effector cells.

One method commonly used to abrogate the tumourigenicity while maintaining immunogenicity of tumour cells is $\gamma$-irradiation. Tumour cells treated with various doses of irradiation $(1,000-16,000 \mathrm{cGy})$ were given s.c. to syngeneic mice $\left(10^{6} /\right.$ mouse $)$ and the development of tumours was examined for up to 60 days (Table 2). Doses of $\geqslant 4000$ cGy were found to be sufficient to inhibit active growth of the tumour. Similar results were obtained in the second experiment where $10^{7}$ tumour cells were tested (Table 2).

Utilizing irradiated tumour cells, we investigated whether normal $\mathbf{B} 6$ mice could be systematically immunized against the BL6 tumour. Mice were inoculated s.c. in the flank with $10^{7}$ irradiated $(12,000$ cGy) BL6 tumour cells admixed with various doses of $C$. parvum $10,25,50,100,200 \mu \mathrm{g})$. These animals

\begin{tabular}{llll}
\hline $\begin{array}{l}\text { Dose of C. parvum }(\mu \mathrm{g}) \\
\text { admixed with BL6 }\end{array}$ & \multicolumn{2}{l}{ Adoptive immunotherapy ${ }^{\dagger}$} \\
\cline { 2 - 4 } & $\begin{array}{l}\text { Activated } \\
\text { LN cells }\end{array}$ & $\begin{array}{ll}\text { In-vivo } \\
\text { L-2 }\end{array}$ & $\begin{array}{l}\text { Mean number pulmonary } \\
\text { metastases (SEM) }\end{array}$ \\
\hline & - & - & $>250$ \\
& - & + & $>250$ \\
0 & + & + & $209(38)$ \\
12.5 & + & + & $8(6) \ddagger$ \\
50 & + & + & $187(30)$ \\
\hline
\end{tabular}

${ }^{*}$ Mice were inoculated s.c. in the flank with $10^{6}$ tumour cells admixed with various amounts of $C$. parvum in $0.1 \mathrm{ml}$ of HBSS. Nine days later, inguinal LN cells were obtained and activated by the anti-CD3/IL-2 method.

$\dagger$ Activated cells $\left(5 \times 10^{7}\right)$ were administered i.v. into mice with 3 -day established pulmonary metastases. IL-2 (15,000 U) was given i.p. twice daily for 4 days starting on the day of cell transfer. Lungs were harvested 14 days after tumour inoculation.

$\ddagger P<0.05$ compared with groups without treatment or treated with IL-2 only.
Table 1. Adoptive immunotherapy of BL6 pulmonary metastases with antiCD3/IL-2 activated LN cells derived from mice inoculated with viable tumour cells admixed with $C$. parvum 
were challenged s.c. four weeks later, with $10^{6}$ viable tumour cells in the opposite flank to determine if systemic immunity was developed. Unlike immunization with previously defined MCA sarcomas, such as MCA 105, MCA 106, MCA 205 and MCA $207[1,21]$, no demonstrable systemic immunity could be detected (data not shown). These observations further substantiated that the BL6 is a poorly immunogenic tumour.

\section{Draining LN response to irradiated BL6 tumour admixed with $C$. parvum}

A vaccine comprised of irradiated BL6 tumour cells and $C$. parvum was evaluated for its ability to elicit a pre-effector cell immune response in draining $L N$. Various numbers of irradiated $(4,000 \mathrm{cGy})$ tumour cells were admixed with $12.5 \mu \mathrm{g}$ of $C$. parvum and inoculated s.c. in the flank of B6 mice. Nine days later, draining inguinal LN were harvested for antiCD3/IL-2 activation. The antitumour reactivity of the activated LN cells was assessed in the adoptive immunotherapy of 3-day established pulmonary metastases as previously described (Table 3). Mice inoculated with $1.2 \times 10^{6}$ irradiated tumour cells and C. parvum did not elicit pre-effector cells because activated cells did not mediate tumour regression. In contrast, the same number of viable tumour cells admixed with $12.5 \mu \mathrm{g}$ of $C$. parvum was effective in eliciting immune pre-effector cells as demonstrated in Table 1. Therefore the difference in immunogenicity between irradiated and viable tumour cells

Table 2. Tumourigenicity of BL6 tumour after irradiation

\begin{tabular}{rll}
\hline $\begin{array}{l}\text { Tumour irradiation } \\
\text { dose (cGy) }\end{array}$ & \multicolumn{2}{l}{ Tumour incidence* } \\
\cline { 2 - 3 } & $10^{6}$ & $10^{7}$ \\
\hline 0 & $5 / 5$ & $6 / 6$ \\
1,000 & $5 / 5$ & - \\
2,000 & $5 / 5$ & $6 / 6$ \\
4,000 & $0 / 5$ & $0 / 6$ \\
8,000 & $0 / 5$ & $0 / 6$ \\
16,000 & $0 / 5$ & $0 / 6$ \\
\hline
\end{tabular}

* Mice were inoculated s.c. with $10^{6}$ or $10^{7}$ BL6 tumour cells in 0.5 of HBSS after various doses of irradiation. The incidence of tumour growth at the inoculation sites was observed over a 60-day period. appeared to be quantitative rather than qualitative. However, vaccines that consisted of a greater number of irradiated tumour cells $\left(\geqslant 6 \times 10^{6}\right)$ were capable of stimulating the sensitization of pre-effector cells in the draining LN (Table 3).

In another experiment, the effect of increased doses of tumour irradiation on the efficacy of the tumour vaccine was examined. B6 mice were inoculated s.c. in the flank with $12.5 \mu \mathrm{g} C$. parvum admixed with $10^{7}$ BL6 tumour cells which were treated with graded doses of irradiation (4,000-32,000 cGy). Nine days later, draining $L N$ were harvested and activated by the anti-CD3/IL-2 method. The antitumour reactivity of the activated cells was assessed again in the adoptive immunotherapy of pulmonary metastases, as previously described (Table 4). All mice inoculated with irradiated tumour cells plus $C$. parvum developed immune pre-effector cells that mediated potent tumour regression after in-vitro activation. Hence, the dose of tumour irradiation did not seem to alter the immunogenicity of the tumour vaccine. More importantly, there was no evidence of progressive tumour growth at the site of vaccination.

Table 3. Adoptive immunotherapy of BL6 pulmonary metastases with anti-CD3/IL-2 activated LN cells derived from tumour-vaccinated mice

Number of irradiated tumour cells admixed with

C. parvum for vaccination*

Adoptive immunotherapyt IL-2 Mean number of puimonary metastases (SEM)

\begin{tabular}{lcc}
\hline A & - & $>250$ \\
B $1.2 \times 10^{6}$ & + & $>250$ \\
C $1.2 \times 10^{6}$ & + & $189(17)$ \\
D $6 \times 17)$ \\
E $3 \times 10^{7}$ & + & $1(1)$ \\
\hline
\end{tabular}

*Mice were inoculated s.c. in the flank with varying numbers of irradiated (4,000 cGy) BL6 tumour cells admixed with $12.5 \mu \mathrm{g} \mathrm{C}$. parvum in $0.1 \mathrm{ml}$ HBSS. Nine days after inoculation, inguinal $L N$ cells were obtained and activated by the anti-CD3/IL-2 method.

$\dagger$ Activated cells $\left(5 \times 10^{7}\right)$ were administered i.v. into mice with 3-day established pulmonary metastases. IL-2 (15,000 U) was given i.p. twice daily for 4 days starting on the day of cell transfer. Lungs were harvested 14 days after tumour inoculation.

${ }_{t}^{+} P<0.05$ when compared with groups $A, B$ and $C$. 
Table 4. The amount of tumour irradiation does not alter the antigenicity of the tumour vaccine

\begin{tabular}{lll}
\hline $\begin{array}{l}\text { Tumour vaccine } \\
\text { irradiation dose } \\
\text { (cGy)* }\end{array}$ & \multicolumn{2}{l}{ Adoptive immunatherapy $\dagger$} \\
\cline { 2 - 3 } & $\begin{array}{l}\text { In-vivo } \\
\text { IL-2 }\end{array}$ & $\begin{array}{l}\text { Mean number of pulmonary } \\
\text { metastases (SEM) }\end{array}$ \\
\hline A - & - & $>250$ \\
B - & + & $>250$ \\
C 4,000 & + & $12(3) \ddagger$ \\
D 8,000 & + & $7(4) \ddagger$ \\
E 16,000 & + & $5(2) \ddagger$ \\
F 32,000 & + & $6(12) \ddagger$ \\
\hline
\end{tabular}

* Mice were vaccinated s.c. in the flank with $1 \times 10^{7}$ irradiated $(4,000-32,000 \mathrm{cG})$ tumour cells admixed with $12.5 \mu \mathrm{g}$. C. parvum in $0.1 \mathrm{ml}$ HBSS. Nine days after inoculation, inguinal LN cells were obtained and activated by the anti-CD3/IL-2 method.

†Adoptive immunotherapy of 3-day established BL6 pulmonary metastases were pertormed as described in Table 3.

$\ddagger P<0.05$ compared with groups without treatment or treated with only IL-2.

\section{Kinetics of pre-effector cell sensitization after tumour vaccination}

The kinetics of pre-effector cell sensitization after tumour vaccination were examined. Groups of B6 mice were inoculated s.c. with $10^{7}$ irradiated 44,000 cGy) BL6 tumour cells admixed with $12.5 \mu \mathrm{g} \mathrm{C}$. parvum every few days so that draining $L N$ could be harvested on the same day. During the observed $19-$ day period, there was a hyperplastic response in the draining $L N$ which peaked on day 9 of vaccination and decreased thereafter (Fig. 1). The vaccine-draining $L N$ cells were activated by the anti-CD3/IL-2 culture method and subsequently assessed for antitumour reactivity in vivo, as described (Table 5). Sensitized pre-effector cells were present as early as 4 days after tumour vaccination and persisted to day 14 before it began to diminish. By day 19, there were no detectable pre-effector cells in the draining LN.

\section{DISCUSSION}

Experimental evidence indicates that properly sensitized T-cells are extremely potent mediators of tumour rejection. Several laboratories have shown that animals immunized to tumours can serve as

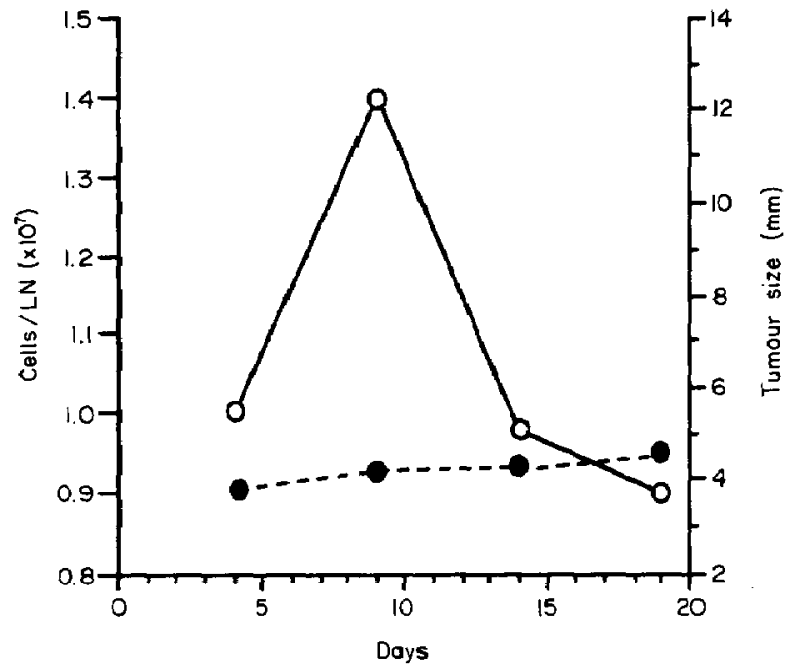

Figure 1. Kinetics of pre-effector cell response after tumour vaccination. B6 mice were inoculated with $10^{7}$ irradiated (4,000 cGy) BL6 tumour cells admixed with 12.5 $\mu \mathrm{g} \mathrm{C.} \mathrm{parvum}$. There was no evidence of tumour growth during the 19-day observation period. A dramatic hyperplastic response in the draining LN was evident on day 9 after tumour vaccination. (- -1 Cells/LN, $(\longrightarrow-1$ ) tumour size.

donors for immune cells which upon transfer, mediate the regression of localized or advanced tumour in syngeneic hosts [6-8]. Also, animals successfully treated by the transfer of immune cells will reject subsequent challenges of the same tumour due to the establishment of systemic immunity in the host. However, there are formidable obstacles which need to be resolved before this approach can be applied to the therapy of malignancy in man. Foremost is the lack of reliable techniques to isolate and produce adequate numbers of tumour-reactive cells needed for adoptive immunotherapy. Unlike animal studies, cancer patients usually do not have genetically identical counterparts to immunize and generate donor immune cells. Therefore, application of adoptive immunotherapy in man will require methods to obtain antitumour-reactive T-cells from the patient. In addition, human cancers have been postulated to be poorly immunogenic because of their spontaneous origin; and might not be analogous to experimentally induced animal tumours, many of which express tumour-specific antigens.

To address these concerns, we have recently developed a culture method which promotes the differentiation and growth of therapeutic T-cells 
Table 5. Kinetics of pre-effector cell sensitization in draining $L N$ after tumour vaccination

\begin{tabular}{|c|c|c|}
\hline \multirow{2}{*}{$\begin{array}{l}\text { Days after vaccination when } \\
\text { draining LN were harvested } \\
\text { for anti-CD3/IL-2 activation* }\end{array}$} & \multicolumn{2}{|c|}{ Adoptive immunotherapy } \\
\hline & $\mathrm{IL}-2$ & $\begin{array}{l}\text { Mean number of pulmonary } \\
\text { metastases (SEM) }\end{array}$ \\
\hline A & - & $>250$ \\
\hline B - & + & $244(6)$ \\
\hline C 4 & + & $3(3) \div 5$ \\
\hline D 9 & + & $10(3) \mp 5$ \\
\hline E 14 & + & $109(19) \div$ \\
\hline F 19 & + & $214(15)$ \\
\hline
\end{tabular}

* Mice were vaccinated s.c. with $10^{7}$ irradiated (4,000 cGy) BL6 tumour cells admixed with $12.5 \mu \mathrm{g} C$. parvum at various intervals prior to harvesting draining inguinal $L N$ on the same day for activation by the anti-CD3/IL-2 method.

†Adoptive immunotherapy of 3-day established BL6 pulmonary metastases was performed as described in Table 3 .

$\frac{1}{T} P<0.05$ compared with groups $A, B$ and $F$.

$\S P<0.05$ compared with group $E$. derived from the tumour-bearing hosts for adoptive immunotherapy. This culture method involves the activation of tumour-draining $\mathrm{LN}$ cells with anti-CD3 $\mathrm{mAb}$ for 2 days followed by expansion in IL-2 for 3 days [14-16]. Utilizing several immunogenic MCAinduced murine sarcomas, we found that activated cells had potent antitumour effects in adoptive immunotherapy experiments. In contrast, similarly activated normal lymphoid cells did not generate tumour-reactive effector cells. These findings suggest that progressive tumour growth stimulate an immune response developed in the draining $L N$ cells, which we have termed 'pre-effector cells'. This terminology was chosen because these cells, when freshly harvested, were not functionally active in adoptive immunotherapy and the generation of therapeutic effector cells required the secondary anti-CD3/IL-2 activation.

The presence of pre-effector cells within the draining $L N$ was critically dependent on the duration of tumour growth. Prolonged tumour growth resulted in the loss or inhibition of pre-effector cells [15]. Perhaps more importantly, there was a virtual absence of a pre-effector cell response in the draining $L N$ during the growth of a poorly immunogenic tumour, the BL6 melanoma (Table 1). However, the admixture of the bacterial adjuvant $C$. parvum at the time of BL6 inoculation did result in the development of pre-effector cells. The ability to elicit a preeffector cell response against BL6 was highly dependent upon the amount of $C$. parvum used and was more effective at lower doses. The use of $C$. parvum did not result in growth inhibition or regression of the BL6 tumour at the inoculation sites. These observations would be difficult to extrapolate for clinical application. We therefore explored the efficacy of a non-tumourigenic vaccine to trigger the pre-effector cell response. In order to define requirements for such a vaccine, which can be applied to poorly immunogenic human cancers, we examined the use of irradiated BL6 tumour cells. We found that irradiation doses of 4,000 cGy or greater could effectively suppress tumourigenicity when $10^{6}$ or $10^{7}$ cells were used as an inoculum (Table 2). As growth of viable BL6 tumour did not elicit a pre-effector cell response in the absence of $C$. parvum, we examined the use of varying numbers of irradiated tumour cells, admixed with a dose of C. parvum, to sensitize pre-effector cells. Although effective in stimulating a pre-effector response in draining LN (Table 3), considerably higher numbers of irradiated tumour cells were required than with viable tumour cells (Table 4). The mechanisms by which $C$. parvum facilitated sensitization to BL6 tumour antigen are unknown; however, there have been several reports documenting the immune effects of this adjuvant. One possibility may be more effective antigen processing by macrophages because $C$. parvum is a known stimulator of macrophages [22]. Alternatively, $C$. parvum may have an adjuvant role by recruiting 
lymphocytes to the tumour site with subsequent elaboration of cytokines that up-regulate an antitumour immune response [23-25].

The pre-effector cell response to the tumour vaccination was also dependent upon the kinetics of vaccination. We found that pre-effector cells were detectable as early as 4 days after tumour vaccination but rapidly declined from day 14 to 19 (Table 5). The suppression of the immune response could not be attributed to non-specific effects of tumour growth because there was no evidence of tumour growth at the vaccination site. One possible mechanism for this immune suppression may be the development of tumour suppressor cells. Our laboratory has previously demonstrated that the pre-effector cell response to growing subcutaneous tumour can be suppressed by the presence of visceral metastases [26]. In additional studies, we have been able to adoptively transfer splenocytes from visceral tumour-bearing mice into normal animals and subsequently identify suppression of the pre-effector cell response to a subcutaneous inoculation of tumour [27]. These observations indicate that the pre-effector cell response can be down-regulated by tumour-induced suppressor cells. Further studies to elucidate the mechanism of this suppression, and methods to overcome it, are clinically relevant.

In other studies, we have further characterized the phenotypic and functional properties of activated pre-effector cells elicited by BL6 tumour and C. parvum (J. D. Geiger, manuscript in preparation). Upon anti-CD3/IL-2 activation, $L N$ cells draining BL6 tumour admixed with $C$. parvum demonstrated a predominance of $\mathrm{CD}^{+}$cells compared with $\mathrm{CD} 4^{+} \mathrm{T}$ cells. Utilizing a $4-\mathrm{h}{ }^{51} \mathrm{Cr}$ release assay, these activated cells did not mediate in-vitro cytolysis of BL6 targets although these same targets were readily lysed by LAK cells. Despite the inability to lyse BL6 tumour in vitro, these activated LN cells mediated the specific regression of BL6 pulmonary metastases and not other immunologically distinct MCA sarcoma tumours. The mechanisms by which anti-CD3/IL-2 activated effector cells mediate in-vivo tumour regression are unknown but may involve the elaboration of cytokines [28], or further differentiation into cytolytic cells upon tumour interaction after adoptive transfer.

The data presented in this report demonstrate the feasibility of generating therapeutic immune cells to a poorly immunogenic tumour with the aid of a nontumourigenic vaccine. In this regard, the tumour vaccine serves to stimulate a pre-effector cell response which requires further in-vitro activation to develop into mature, functionally active therapeutic effector cells. We are currently exploring this approach in the treatment of patients with advanced malignancies. Initial observations have indicated that immune reactivity to autologous tumour is transferred and tumour regression has been noted in some patients [29]. Future directions with this therapeutic approach involve methods to enhance preeffector cell sensitization. We have investigated the use of exogenously administered cytokines to determine if pre-effector cell sensitization can be upregulated. We have found that $\mathrm{IL}-1$ administration can significantly enhance the pre-effector cell response while there is no effect with exogenously administered IL-2 [30]. In addition, we found that the administration of TNF $\alpha$ will down-regulate the preeffector cell response [31]. Another manipulation, which may lead to an enhanced pre-effector cell sensitization, is the use of genetically modified tumours. Several recent studies have demonstrated that the transduction of murine tumour cells with genes encoding cytokines (i.e. IL-2, IL-4, TNF $\alpha$ ) alter the immunological properties of tumours [32-34]. This may provide an alternate approach to developing a pre-effector cell response to poorly immunogenic tumours which our laboratory is currently investigating [35].

\section{ACKNOWLEDGEMENTS}

This study was supported in part by the Boston Foundation, Boston, MA, the Geiger Cancer Research Foundation, Toledo, $\mathrm{OH}$ and the James Ewing Student Fellowship (PDW). The authors wish to thank Ms Debbie Birdsall for her excellent assistance in preparing this manuscript.

\section{REFERENCES}

1. Shu S, Rosenberg SA. Adoptive immunotherapy of newly induced murine sarcomas. Cancer Res 1985; 45: 1657-62.

2. Barth RJ, Bock SN, Mule JJ, Rosenberg SA. Unique murine tumor-associated antigens identified by tumor 
infiltrating lymphocytes. I Immunol 1990; 144: 1531-7.

3. Stevenson FK. Tumor vaccines. Faseb / 1991; 5: 2250-7.

4. Berd D, Maguire Jr HC, McCue P, Mastrangelo MJ. Treatment of metastatic melanoma with an autologous tumor-cell vaccine: clinical and immunologic results in 64 patients. J Clin Oncol 1990; 8: 1858-67.

5. Hoover Jr HC, Hanna MC. Active immunotherapy in colorectal cancer. Sem Surg Oncol 1989; 5: 436-40.

6. Cheever MA, Greenberg PD, Fefer A. Tumor neutralization, immunotherapy, and chemoimmunotherapy of a friend leukemia with cells secondarily sensitized in vitro: II. Comparison of cells cultured with and without tumor to noncultured immune cells. $J$ Immunol 1978; 121: $2220-7$.

7. Eberlein TJ, Rosenstein M, Rosenberg SA. Regression of a disseminated syngeneic solid tumor by systemic transfer of lymphoid cells expanded in interleukin-2. $J$ Exp Med 1982; 156: 385-97.

8. Shu S, Chou T, Rosenberg SA. In vitro sensitization and expansion with viable tumour cells and interleukin 2 in the generation of specific therapeutic effector cells. $J$ Immuno/ 1986; 136 : 3891-8.

9. Rosenberg SA, Spiess P, Lafreniere R. A new approach to the adoptive immunotherapy of cancer with tumor-infiltrating lymphocytes. Science 1986; 233: 1318-21.

10. Spiess PJ, Yang JC, Rosenberg SA. In vivo antitumor activity of tumor-infiltrating lymphocytes expanded in recombinant interleukin-2. JNC/ 1987; 79: 1067-75.

11. Rosenberg SA, Packard BS, Aebersold PM, et al. Use of tumor-infiltrating lymphocytes and interleukin-2 in the immunotherapy of patients with metastatic melanoma. A preliminary report. NEJM 1988; 319: 1676-80.

12. Shu $S$, Chou $T$, Rosenberg SA. Generation from tumor-bearing mice of lymphocytes with in vivo therapeutic efficacy. J Immuno/ 1987; 139: 295-304.

13. Chou T, Bertera S, Chang AE, Shu S. Adoptive immunotherapy of microscopic and advanced visceral metastases with in vitro sensitized lymphoid cells from mice bearing progressive tumors. I Immunol 1988; 141: 1775-81.

14. Yoshizawa H, Sakai K, Chang AE, Shu S. Activation by anti-CD3 of tumor-draining lymph node cells for specific adoptive immunotherapy. Cell Immunol 1991; 134: 473-9.

15. Yoshizawa $H$, Chang AE, Shu $S$. Specific adoptive immunotherapy mediated by tumor-draining lymph node cells sequentially activated with anti CD3 and IL-2. J Immuno/ 1991; 147: 729-37

16. Yoshizawa $H$, Chang AE, Shu $S$. Cellular interactions in effector cell generation and tumor regression mediated by anti-CD3/Interleukin-2 activated tumor draining lymph node cells. Cancer Res 1992; 52: 1129-36.

17. Hewitt HB. Second point: animal tumor models and their relevance to human tumor immunology. I Biol Resp Modif 1983; 2: 210-16.

18. Hart IR. The selection and characterization of an invasive variant of the $\mathrm{B} 16$ melanoma. Am J Pathol 1979; 97: 587-600.

19. Nathanson SD, Haas GP, Mead MJ, Lee, M. Spontaneous regional lymph node metastases of three variants of the B16 melanoma: relationship to primary tumor size and pulmonary metastases. $J$ Surg Oncol 1986; 33: 41-5.

20. Portoles P, Rojo J, Golby A, et al. Monoclonal antibodies to murine $\operatorname{CD} 3 \varepsilon$ define distinct epitopes, one of which may interact with $\mathrm{CD} 4$ during $T$ cell activation. $\mathrm{J}$ Immunol 1989; 142: 4169-75.

21. Barth RJ, Bock SN, Mule JJ, Rosenberg SA. Unique murine tumor-associated antigens identified by tumor infiltrating lymphocytes. J /mmuno/ 1990; 144: 1531.

22. Bomford $R$, Christie GH. Mechanisms of macrophage activation by Corynebacterium parvum II. In vivo experiments. Cell Immunol 1975; 17: 150.

23. Emeson EE. Adjuvant-induced selective recruitment of specifically reactive lymphocytes: A probable mechanism of adjuvant action. $J /$ mmunol 1980; 124: 2222.

24. McCune CS, Marquis DM. Interleukin 1 as an adjuvant for specific immunotherapy in a murine tumor model. Cancer Res 1990; 50: 1212.

25. Bosco $M$, Giovarelli $M$, Forni $M$, et al. Low doses of IL-4 injected perilymphatically in tumor-bearing mice inhibit the growth of poorly and apparently nonimmunogenic tumors and induce a tumor-specific immune memory. $J / m m u n o / ~ 1990 ; 145: 3136$.

26. Sondak VK, Wagner PD, Shu S, Chang AE. Suppressive effects of visceral tumor on the generation of antitumor $T$ cells for adoptive immunotherapy. Arch Surg 1991; 126: 442-6.

27. Sondak VK, Tuck MK, Shu S, Chang AE. Transfer of specific tumor-induced immunosuppression by splenoocytes from visceral tumor-bearing mice (Abst. 1928). Proc Am Assoc Cancer Res 1992; 33: 323.

28. Barth RJ, Mule JJ, Spiess PJ, Rosenberg SA. Interferon $\gamma$ and tumor necrosis factor have a role in tumor regressions mediated by murine $\mathrm{CD}^{+}$tumor-infiltrating lymphocytes. J Exp Med 1991; 173: 647

29. Chang $A E$, Yoshizawa $H$, Shu $S$. Sensitized $T$ cell therapy of human cancer (Abst. 1486). Proc Am Assoc Cancer Res 1991; 32: 250.

30. Sondak VK, Tuck MK, Shu S, Yoshizawa H, Chang AE. Enhancing effect of interleukin $1 \alpha$ administration on antitumor effector $\mathrm{T}$ cell development. Arch Surg 1991; 126: 1503. 
31. Wagner PD, Shu S, Chang AE. Divergent effects of TNF $\alpha$ in the adoptive immunotherapy of a murine sarcoma. J Surg Res 1992; 53(2): 152-7.

32. Fearon ER, Pardoll DM, Itaya $\mathrm{T}$, et al. Interleukin-2 production by tumor cells bypasses $\mathrm{T}$ helper function in the generation of an antitumor response. Cell 1990; 60: 397-403.

33. Asher AL, Mule JJ, Kasid A, et al. Murine tumour cells transduced with the gene for tumor necrosis factor- $\alpha$. Evidence for paracrine immune effects of tumor necrosis factor against tumors. $J$ Immunol 1991; 146: 3227-34.

34. Golumbek PT, Lezenby AJ, Levitsky HI, et al. Treatment of established renal cancer by tumor cells engineered to secrete interleukin-4. Science 1991; 254: 713-16.

35. Wahl WL, Plautz GE, Fox BA, Nabel GJ, Shu S, Chang $A E$. Generation of therapeutic $T$ lymphocytes after in vivo transfection of tumor with a gene encoding allogeneic class I MHC antigen. Surg Forum Vol. XLIII, 1992. 